\title{
Stress, and Deconcentration of Children in Learning, and Their Involvement in Work
}

\author{
Prof. Ass. Dr. Behxhet Gaxhiqi
}

University of Gjakova - Faculty of Education, Gjakovo, 50000 Municipality Gjakovo, Republic of Kosovo

\begin{abstract}
The key research problem in this regard is familiarizing with the causes and motives of engaging children at work; and knowing the factors influencing in spreading this occurrence which is of a large extent and very concerning, for the fact that this occurrence is being increased every day more and more. The occurrence of studying these issues and familiarizing with the circumstances, also the impellent and motivating factors in this aspect, has affected the change of this situation to a large extent. The reason to choose this topic for research among others is the study method of this issue, since it is one of the most spread problems among children nowadays, because a number of them perform heavy duties and with destructive measures for their health as in the psychic aspect and also in that emotional one, but also in the bad construction of the child's personality. However, on the occasion of knowing and studying of these circumstances today, we primarily have a better awareness as in this cases to the parents-family, social-cultural environment and also the society in general. Our research problem in this case will be "causes and motives of engaging children at work". This will be our research focus in this regard.
\end{abstract}

Keywords: familiarizing, circumstances, influencing, the parents-family, social-cultural

\section{Introduction}

\section{2. Review / checking the literature}

Purposely to efficacy of work in this regard, we have specified a measure of checking the literature so that it will have a wider dimension of inclusion of key elements in this regard. We have selected a basic literature responding to the specifics of qualitative research.

We should emphasize the nature and the work methodology for this research since we are aware that we should fit the literature with controlling value dimensions for the research, because selection of literature is of an important aspect.

Among others, we have specified that each part of the research work should be reviewed and the literature to be checked because an appropriate selection of this brings a higher productivity and efficacy in the learning work and wider.

Our focus in this research is on the children works which do not respond to the age and psychic-physical skills of children, thus the types of work and duration of engagement at work.

Otherwise, we are aware for the need of engaging children at work which correspond to the abilities, needs and their skills. This research has a multifold importance: above all this is the first qualitative research in Kosovo on the occurrence of involvement of children at work.

By means of this research, the awareness of opinion on the spread of this phenomenon is achieved to be realized. The main causes that stimulate this phenomenon are made known and we also come to know the physical and psychic-social consequences for children.

Data derived by the means of this research will serve to the institutions dealing with social problems in order to have an information overview that is the basis for the preparation of social policies related to this problem. In addition, this research will serve as a basis for the future research and we believe it will serve, either in a modest manner, in the general awareness of parents, teachers, children and all those who in a form or another are related to this issue. 
For the adaptation of literature and its checking, we have tried to do a comparison of the review and checking of literature in conformity with the research procedures, because its design from the beginning has brought productivity in this regard.

\section{Methodology and Methods}

We have come up to the identification of causes, motives and consequences of engaging children at work through the usage of research instruments: interview, observations, case studies and focus groups. Advantages and disadvantages were selected to be discussed for topics related to certain problems through the issues mentioned above.

These research instruments were used with children, with some of their families, with schools, with CSL, with relevant institutions related to this problem and with all target groups. 200 interviews, 6 case studies and 2 focus groups were realized. The data collected through this qualitative research were analyzed socially, pedagogically, psychologically and legally.

In this research it has been discussed on the history of inclusion of children at work both in the world and here. Additionally, the social background was presented including the economical state and education policies in Kosovo.

As a result of the data we came to the conclusion that the inclusion of children at work comes as a result of many causes: Poverty, war consequences,

Other family tragedies,

Social inequality,

Social and cultural level and migration - mobility within Kosovo (from the rural localities into those urban ones).

Among motives, the following ones are presented:

Independence motive,

Motive for gaining wealth and motive of security.

From this specific of the work, we can ascertain that poverty and war consequences will continue to be a problem in the future.

We should specify this issue since poverty still remains on the biggest challenge in this aspect due to the fact that the high scale of poverty is aggravating the situation of families in a difficult social state, especially of those families which have a difficult economical situation; and poverty is one of the main causes in inclusion of children at execution of different and heavy duties.

The consequences of involvement of children at work based on our research may be characterized in: consequences on children, consequences on families and consequences on the society. Involvement of children at work has physical effects on children themselves, physical-social effects and social-economical effects.

Within these consequences there are stress, inattention, tiredness, loss of wish for peers, lack of free time, depression and reclusion, harm of the sense of collectivity - selfishness, school abandonment, decrease of the ability to learn, loss of interest for general cultural development, regression etc.

Additionally, some additional data are presented within the research on the topic "Children at work", such as: working children's age, gender, residence, level of education of children and their families and types of work children perform at their job places.

We have also included in this research the category of children, mainly young girls, why by being engaged in certain job categories may result with their involvement in trafficking.

Within this from the nature of the qualitative research study, we came out with the conclusion that the problems in the future, such as: poverty, war consequences, other family tragedies, social and cultural level and migration - mobility within Kosovo, are problems which will be in continuity in the future since these causes will be further active towards these categories which are in the social need situation.

Kosovo society is passing through a political and economical transition. War destructions have aggravated the economy of Kosovo families and social-owned and private enterprises. As a consequence, the number of unemployed has increased 
to a high extend. By this, and according to the report of World Bank on the poverty level in Kosovo, it comes out that around $50 \%$ of the Kosovo society lives in poverty, whereas $12 \%$ in extreme poverty.

Almost all children involved come from families with different economical conditions and children work for their families in different informal sectors.

Almost all children work in bad hygienic conditions, extreme temperatures, with dangerous-sharp tools, toxic substances; they are exposed to various noises, long working hours, closed environments etc.

The majority combines school with work, they work before of after the school hours but some are also absent sometimes.

All belong to the primary school, of 7-14 years old.

Services which are foreseen with the project have been those: referring to regular and accelerated learning depending on the current situation of the child who has abandoned the school, individual consultations for children and family consultations for parents related to risks of work, after school hours for children in order to improve the success and their attendance at school; group awareness and socializing activities for children; other informal educational activities such as different courses and other additional services provided in order to serve for specific needs of the targeted children.

Providing after school hours: in total 606 children have benefited from after school hours.

All the targeted children and their families have received family and individual awareness advising related to children work and risks. These consultations were done in close cooperation with Case managers from CSL and teachers from schools.

Rehabilitation and awareness sessions were realized in all municipalities.

Other informal education activities: different courses which expenditures were covered by the project: English language and computer courses were enabled for 98 referred children (Prizren 35 children in three months courses, Gjilan 13, Drenas 30 and Kastriot 20 children) (12 children in computer course and 8 in English language course).

Activities through referring to other existing institutions:

2 children involved in vocational training courses through referring to the Vocational Training Center (Prizren and Mitrovica) whereas 41 family members of 28 families were referred to the employment office. 12 children involved in English language courses in the center CPVPT through referring in the other project of this center (Prishtina). 50 children in English language courses, informatics and Albanian language through referring to the NGO "Buzëqeshja" (Smile) (Mitrovica). 13 children involved in sport activities - football through referring to the Department for Culture, Youth and Sport (Mitrovica). Issuance of birth certificate for one child through referring to the NGO CRPK (Prizren). 53 cases (Prishtina, Drenas, and Mitrovica) have received meat from the sacrificed animal from 94 cases referred to the Islamic Community.

In the Municipality of Kastriot, 17 children have participated in an 8-week awareness campaign through referring to the NGO "Aureola". The activity is organized in daily workshops on different social topics. 110 targeted children (Prishtina) have benefited daily food from "Buqaj" company on the occasion of a group activity with children organized on the day against children abuse on 19 November 2008.

\section{1. Methods, study projecting, which approach will you use and why?}

In this research, our focus is addressed in the children work which does not respond to the age and psychic-physical skills of children, that means types of work and duration of engagement at work.

On the contrary, we are aware for the need to engage children at works corresponding to the capacities, needs and their abilities.

This research has multifold importance: above all this is the first qualitative research in Kosovo on the occurrence of involvement of children at work.

By means of this research, the awareness of opinion on the spread of this phenomenon is achieved to be realized.

The main causes that stimulate this phenomenon are made known and we also come to know the physical and psychicsocial consequences for children. Data derived by the means of this research will serve to the institutions dealing with social 
problems in order to have an information overview that is the basis for the preparation of social policies related to this problem.

In addition, this research will serve as a basis for the future research and we believe it will serve, either in a modest manner, in the general awareness of parents, teachers, children and all those who in a form or another are related to this issue.

A series of methods and research techniques have been used in the study of the research problem. Among the main ones are: method of theoretical analysis, experimental method and research survey method.

By the means of each of this method we have emphasized a series of problems which have been unnoticed and no research was done on them until now.

Method of theoretical analysis - this method has taken a special place in our research since the main reviews and empirical research of causes of engagement of children at work are shown through this method.

In addition, through this method we have derived data which came out from the collection of this problem in order to know which are the main factors in the inducement and involvement of children at work.

By using this theoretical method, we collected the data of different authors, either those local or international ones who dealt directly with this study area related to engagement of children at work and impellent factors in this process.

Through this method we have also collected data that which of the authors has written about this problem of involvement of children at work, how much was this form studied until now, the model of the study of such a nature and how much it found viability in the society so that this phenomenon with negative dimensions to be studied and lighten in a higher extent of the study.

\section{2. Statistical methods}

This method of a huge importance and weight also takes a big part in our research due to the fact it has the special weight to express statistically the results deriving from the research done in the field, and concretely in those places where children are the most involved at work.

This method in our work during this qualitative research enables us to collect data, to analyze them, to elaborate, to compare, to interpret, because through this method, the results derived from the qualitative research are expressed statistically.

In addition, through the statistical method we have the relevant research indicators, issuance of graph tables deriving from data of the empirical research, then presentation of data tables, manner of their elaboration in practice.

In addition, through this method we have come up with the relevant indicators which verify the hypothesis of this project raised during the research phase.

Additionally, through this method we will tell for their level deriving from the research, about the research nature on the causes and motive of engaging children at work.

\section{3. Testing method}

Through this procedure we achieved to collect data from children as regards their general skills: which work they perform more often and which work is harder for them to perform.

In addition, in this framework, the age of children who work should be known and meanwhile which gender is more involved in this work process.

And after this procedure of testing exercises, we came up with the final situation of the causes and motives of involvement of children at work and execution of heavy works which is outside of the international norms allowed based on the conventions.

However, from this came out that in the framework of the testing method were emphasized which types of works are more dangerous for children, as: agriculture and forestry, work at streets, collection of waste for recycling, work in the exploitation 
of natural resources, operation with agricultural equipments, splashing with pesticides, work in harvesting-threshing, hard physical works in fields, wood cutting, work in butchery (butcher of animals and carrying killed animals)

\section{4. Surveying technique}

We have used the surveying technique or procedure to collect facts from pupils and teachers, as well as purposely to better data elaboration which served in drawing the sample about the empirical research.

We have developed the surveying technique divided in two phases.

The first phase was held with children who were identified as: street sellers of cigarettes and other small articles, beggars inside and outside the country, pusher, children who work as prostitutes, children used in agricultural and farming activities, fisherman with different tools and so on.

Whereas in the second phase of review we have organized it concretely with the parents of children we have identified being working in order to know the cause and meantime their motive on why their children are working, and meantime to identify the survey side on which is the main factor of involvement of children at work.

This approach and surveying method enabled and facilitated our qualitative research work among others also for the division of children group ages which are involved in executing different works.

In the second phase, the survey was done with parents and also with teachers. This survey was done through questionnaires. Questions were open and some closed, whereas two of them have had alternatives.

Method of pedagogical documentation

In addition, as with the other methods used above and by the means of this method which is very important in this period of qualitative research, respectively related to the data collection which assists us a lot in this phase of the survey research work.

This method is applied for collecting relevant data of the written documentation on schools, teachers and pupils, in order to know how much data do we have in this regard, whether their pupils are attending school or they are abandoning it due to the hard economical situation and this is why they are involved at work; and how much has been done in this field.

After completing the experiments, techniques and respective procedures, teachers of the working classes were interviewed in the research phases in learning.

By implementing this technique with the prepared questions, responses which express the opinions of teachers on their concern were given since in each of the learning hours where they teach there is one or two pupils absent at school and who due to the difficult economical-social situation do not attend classes since they have to work in order to take care for their family.

The abovementioned methods were used as strong points on collecting data due to the fact that a series of problems of different natures but related to this issue of the qualitative research was derived through these methods.

Experimental method

This method has a merit place in each research and with a special weight since the nature and specifics of each research depends to a high extent on this important method in this research-scientific working phase, as well as in the qualitative research.

In each flow of research is important to know the value and weight of the experimental procedures of research during the research phases.

In each research, experiments with different pupils are used, and in our case the experiment with children working and identified in streets was used as well as another group of children who were identified in execution of work in forestry and agriculture. 
These selections of experimental methods respond the best to our hypothesis raised in the qualitative research.

Taking into account that we aimed to study, research and lighten and verify the causes and motives of engaging children at work, we have chosen the experiment with the two abovementioned groups of children because the confidence in verifying the hypothesis of pupils at learning will be successful since we will not have fluctuation and distractions of results deriving from the qualitative research.

We have developed the experiment in two working phases: one with the first group and the other with the second group.

\section{5. Analytical strategies}

Describe which strategies you will use for data analysis. Develop a plan on the manner of proceeding with the appropriate qualitative approach you have chosen.

In order to be more efficient in this approach, we should emphasize that the analytical strategies within this qualitative project are very important, since we have to do an analysis of the current situation of this nature of the study issue.

In the framework of this study issue, strategies which emphasize the need for emphasized usage of analytical strategies were used.

As an analytical strategy, we should emphasize the need to provide services to these children categories which are identified to be included at work, services which have been foreseen by the project have been these:

referring to regular and accelerated learning depending on the current situation of the child who has abandoned the school, individual consultations for children and family consultations for parents related to risks of work,

after school hours for children in order to improve the success and their attendance at school;

group awareness and socializing activities for children;

other informal educational activities such as different courses and other additional services provided in order to serve for specific needs of the targeted children.

Among these services we may list: food and hygienic packages, food (bread and flour for families), daily food for children, medicaments, school tools, books, payment of transport for children in order to have an easier access in activities; protective tools for the work in agriculture and clothing.

As a special analytical strategy is also the referral and access in the formal education for children who have abandoned the educational process or are not included in schools (where the direct access in the formal education process is possible) as well as the referral into accelerated learning.

Strategies to analyze the data are ascertained through the data derived from questionnaires but also through the survey methods. Based on these data the current situation of these data was analyzed from asking questions and the data derived from the research.

The data analysis can be materialized through comparisons done by collecting data where the findings through questionnaires were concluded and based on those conclusions derived from questionnaires we came up with the analytical strategy of the Results of the questionnaire in reading and comprehension skills of pupils in the low level of primary school.

In order to get to know closely with the flow of research work, and in order to have a higher effectiveness in this research, we have divided the research questionnaire in two phases.

In the first phase of the initial questioning of pupils, we received information on the pupils' level of knowledge, their success at school, their shown results doing learning at school, engagement, their success shown in their mother tongue acquisition.

The aim of collecting these data is to have a clearer view of the issue of motivation and involvement of children at work.

We have foreseen to do the collection of these data by organizing two research groups: one with the group of children involved at work with whom we organized a conversation to verify the cause of engagement of children at work. They will read, comment; ask questions to each other, in order to understand the meaning and the risks for their involvement at work. 
By this fact, we may conclude that through involving children at performing different works it may have an influence on their involvement on the trafficking issue, which is a very negative element for the society and for those children categories in general.

Whereas the other group was custodians, parents and teachers of children-pupils will deal with the check of homework which the working group will do in order to have an efficacy of understanding that which of these groups will show an efficacy related to research data.

\section{6. Data quality.}

Assess your data quality, including the used criteria for assessment and discuss how would you ensure higher data quality.

In the framework of the qualitative research process, we should ascertain that the quality of data included in the research, among others, have shown a high quality of the research value.

This was specified in the framework of data analysis since for this issue we have used the abovementioned indicators. Through these indicators, the nature and value of the qualitative project was specified concretely in the presented sample of cases to be researched.

The accuracy of data consists on the accuracy of the reported data in relation to the data found in the systems of holding data through questionnaires and measurement indicators in this qualitative research process.

The credibility of data consists on that the system of holding data from issuing data corresponds with the current situation in field, since through the analysis on data derived from the qualitative research we may conclude that the data have shown a real credibility because they are based upon the real value of the research. For such credibility, the indicators or measurement factors of this qualitative research were used. It provides credible data, as: credible, less credible, relatively credible, satisfactory credibility, completely credible.

Quantitative research is numerically orientated. It requires special attention on the measurement of market occurrences and it includes statistical analysis. This approach provides quantitative data which may be analyzed precisely. The quality of data is realized in conformity with the usage of these means in the qualitative research, such as:

\section{7. Direct interviews}

We have developed effective procedures for all components of survey in the field, including the identification of the units of sample in this field, field personnel selection and training, developing manuals for the work in field, oversight of interview in field, substitution of rejections and minimization of the extent of not answering, efficient implementation of the qualitative control, as well as the management of the project administration and reporting.

\subsection{Telephone Interviews}

We have the necessary expertise and space for research through telephone. We have provided efficacy and high quality in data collection. Personal contact in cooperation with the surveys through telephone enables the increase of an explanation level which is crucial for the quality of collected data.

\section{9. Qualitative research}

We have completed our research on the causes and motives of engaging children at work through the usage of a series of qualitative research methods which are the following: focus groups, detailed interviews, observer techniques, consumers' presentation, and the consumers' satisfaction. We have used a wide series of qualitative methodologies, and we have chosen our perfect combination which fits to the parameters of each project of qualitative research.

\section{10. Focus groups}

One of the most known techniques of market research is the focus groups of discussion. Focus groups are a good possibility through which the qualitative data collection is done in a fast manner and by observing the interactions of a selected respondents' group.

\section{11. Detailed interviews}

We have used detailed interviews and through them we have presented a technique projected to derive a real view of the 
participants' perspective related to the research topic. The techniques of interviewing by the researcher's side are motivated from the wish to learn everything the participant may share related to the research topic.

\section{12. Observer-techniques}

Through the observer techniques we have enabled the observance of phenomenon in their natural environments. The observance consists of the observance of the attitude and interactions happening and which can be seen by the researcher. The aim is "to adjust to the environment" so that the presence of a foreigner shall not have a direct effect on the phenomenon to be studied.

\section{Political and ethical issues}

How will you ensure the protection of those participants you have used for this research?

What difficulties you expect to face and how will you cope with these difficulties?

At the moment of assigning this qualitative research, among the others, the special specifics of this field in this regard have been emphasized.

The protection of participants is specified within the compilation of questionnaires, since this issue is designed to a high extent in those places where we had higher possibilities to realize the qualitative research with children involved in different jobs. It was easy for us to ensure the participants' list on the questionnaire and survey, since the location we have selected to do the survey with children working in different streets and different places has been a huge one and it had a huge density of involvement of children at work.

However, in the framework of research process, we have faces in some difficulties since some children hesitated to respond to the questionnaire, because this issue to a high extent for the children had a different connotation.

Children who responded to the questionnaires and the survey were afraid since the issue of their involvement at work had intrusion motives from the parents' side so that they work wither during the day or this occurrence is noticed the most during the night in different cafes, which is forbidden according to the international conventions.

We have noticed a readiness of cooperation with these children since it can be worked a lot on this direction and to assist to those children in order to not abandon their school, to be equal with the other children and to attend school, and to abandon this occurrence which has had quite big dimension for the children and parents in general.

The question that how we will cope with these difficulties depends to a higher extent to the nature and approach in this regard, but firstly, we should have cooperation with the parents of these children who based on the interview were noticed to make their children to work. Some other children started to work for the existence of their families due to the difficult economical situation and nature.

One of our mechanisms in this regard among the others will be cooperation with the parents of these children and meanwhile will see how to cooperate with the state institutions in order to assist to these children who are in the state of social need.

Many of the parents with whom we have cooperated hesitate in this regard to emphasize their reason for the children to work, since there have been such ones that have stressed that they don't know that their children work. The latter were shown more cooperating in this aspect to research and lighten this problem to an extent of making aware parents and their family that children should attend school and not to abandon it since this issue may produce negative effects for the society in general.

\section{Discussion and conclusion}

\section{Conclusions derived based on the knowledge on the improvement of political and professional practices.}

To provide protection tools for children working in agriculture.

To increase the cooperation between schools and municipal directorates on agriculture and rural development so that children are provided professional lectures at schools for the work in agriculture.

To stimulate pupils to work in agriculture and to attend professional schools (giving scholarships). 
To increase the cooperation of schools and Municipal Directorates for Youth, Culture and Sport so that children are involved in sport activities.

The representative of the civil society should participate in the Local Action Committees.

To strengthen the youth centers which assess the needs of youths in the community they live and to provide adequate services for those needs.

The volunteers serving in youth centers should be involved in the process of identification of children in the FCSN.

Schools should be attentive to identify on time the cases which are a predisposition to abandon the school and to be included in the FCSN, so by the intersectoral cooperation within the municipality to enable a successful prevention.

The school management should be attentive to ask for professional medical assistance if needed.

To work in the school curricula and to manage so that within certain subject to call experts to lectures or classes on the topics such as: dangerous works, different illnesses and lectures on negative occurrences (trafficking, smoking, alcohol, drug etc.

To have monitoring at a certain level so that the implementation of the legal infrastructure which sanction the work of children will be in place; and also the laws which ensure the attendance in the mandatory educations?

\section{References}

[1] Convention on the most difficult (heaviest) forms of children work (Article 182 of ILO)

[2] Convention on the protection of children rights 1989

[3] Document for discussion at the informal tripartite meeting at the Ministerial level, International Lab our office, Geneva. First published June, 1996.

[4] Focus Kosovo, December 2002

[5] ILO research report-working child, 2000

[6] Law on marriage and family relations, Official Gazette 10/84 Prishtina.

[7] Qualitative study of Diarrhea prevention \& Management - Cuanza Sul, Angola.

[8] Sociology by Anthony Giddens, October 1997

[9] Statistical Office of Kosovo, 2001.

[10] The practice of social research by Earl Babbie, 9th edition, 2001.

[11] Trafficking and violent prostitution, concerning phenomenon for Kosovo

[12] UN Convention on the rights of the child.

[13] UNFPA/IOM, 2000. See the UNDP report on human developments Kosovo, 2002

[14] Youngest workers and hazardous child labour by Kebebew Ashagrie; Bureau of statistics, May 1999. 